\title{
Maintenance of Skill Proficiency for Emergency Skills With and Without Adjuncts Despite the Use of Level C Personal Protective Equipment
}

Harsh Sule $^{1}$, Miriam Kulkarni ${ }^{2}$, Gregory Sugalski ${ }^{3}$, Tiffany Murano ${ }^{1}$

1. Emergency Medicine, Rutgers New Jersey Medical School, Newark, USA 2. Emergency Medicine, St. John's Riverside Hospital, Yonkers, USA 3. Emergency Medicine, Hackensack University Medical Center, Hackensack, USA

Corresponding author: Harsh Sule, harsh.sule@rutgers.edu

\section{Abstract \\ Objective}

To determine the impact of Level C personal protective equipment (PPE) on the time to perform intravenous (IV) cannulation and endotracheal intubation, both with and without the use of adjuncts.

\section{Methods}

This prospective, case-control study of emergency medicine resident physicians was designed to assess the time taken by each subject to perform endotracheal intubation using both direct laryngoscopy (DL) and video laryngoscopy (VL), as well as peripheral IV cannulation both with and without ultrasound guidance and with and without PPE.

\section{Results}

While median times were higher using VL as compared to DL, there was no significant difference between intubation with either DL or VL in subjects with and without Level C PPE. Similarly, no significant difference in time was found for intravenous cannulation in the PPE and no-PPE groups, both with and without ultrasound guidance.

\section{Conclusions}

Existing skill proficiency was maintained despite wearing PPE and there was no advantage with the addition of adjuncts such as video-assisted laryngoscopy and ultrasound-guided intravenous cannulation. A safe and cost-effective strategy might be to conduct basic, just-in-time PPE training to enhance familiarity with donning, doffing, and mobility, and couple this with the use of personnel who have maximal proficiency in the relevant emergency skill, instead of more expensive, continuous, skills-focused PPE training.

Received 03/13/2020

Review began 03/17/2020 Review ended 03/24/2020 Published 03/27/2020

๑) Copyright 2020

Sule et al. This is an open access article distributed under the terms of the Creative Commons Attribution License CC-BY 4.0., which permits unrestricted use, distribution, and reproduction in any medium, provided the original author and source are credited.
Categories: Emergency Medicine, Infectious Disease, Epidemiology/Public Health

Keywords: personal protective equipment, ppe, cbrn, video laryngoscopy, intubation, intravenous, ultrasound, emergency medicine

\section{Introduction}

The health crises related to Ebola Virus Disease (EVD) in 2014 and, currently, coronavirus Disease 2019 (COVID-19) highlighted a key challenge in caring for patients who have or may potentially have chemicalbiological-radiological-nuclear (CBRN) exposures.

Although there are instances where healthcare is deferred until decontamination is complete or the risk of contamination eliminated, there are circumstances where aggressive airway management and hemodynamic stabilization is required with a significant risk of exposure to healthcare providers. Given the high risk of contamination of front-line emergency medicine personnel, the use of appropriate personal protective equipment (PPE) is critical. There are generally two approaches to training exercises - focused training with periodic refresher courses or just-in-time training. The cost burden of preparing for high-risk, lowfrequency events such as CBRN incidents is a significant challenge since it places a financial and personnel/time burden on hospitals [1-3]. Moreover, training exercises tend to focus on donning and doffing $\mathrm{PPE}$, and not procedural competence while in PPE.

In recent years, the use of adjunct devices, such as video laryngoscopy $(\mathrm{VL})$ and ultrasound, has become instrumental in the daily practice of emergency medicine. Conflicting evidence exists in the literature as to whether the use of PPE impedes the ability to simply successfully intubate, and this is further complicated by the impact of VL when using PPE [4-9,10-12]. While there is also conflicting evidence regarding the impact of ultrasound on intravenous (IV) cannulation, there are no studies that address its use with PPE [13-14]. 


\section{Cureus}

Our study is the first to examine these parameters while using both VL for intubation and ultrasound for intravenous cannulation.

Our primary objective was to determine the impact of Level C PPE on the time to perform intravenous cannulation and endotracheal intubation, both with and without the use of adjuncts. We hypothesized that it would take longer to perform these key procedures while donned in PPE.

\section{Materials And Methods}

\section{Ethical consideration}

The study was approved by the Institutional Review Board of Rutgers Newark Health Sciences.

\section{Study design}

This is a prospective, case-control study with self-matching that was performed in the Extended Treatment Area (ETA) of University Hospital (Newark, NJ), which is part of the emergency department (ED) where all patients with suspected CBRN exposure are evaluated and treated. The subjects were emergency medicine (EM) residents in our four-year residency program that had no previous training related to PPE used but were proficient in the technical skills being evaluated. Each resident served as their own control. All study subjects were consented prior to participation.

\section{Equipment}

Participants used PPE certified to provide the maximal level of protection to personnel responding to CBRN agents (Level C). Details of PPE, intravenous cannulation, and endotracheal intubation are shown in Table 1. 


\section{Cureus}

\begin{tabular}{|c|c|c|}
\hline Equipment common name & Manufacturer & Model/Part \\
\hline \multicolumn{3}{|c|}{ Personal Protective Equipment (PPE) } \\
\hline $\begin{array}{l}\text { Powered Air Purifying } \\
\text { Respirator (NIOSH CBRN } \\
\text { Approved) }\end{array}$ & 3M (St. Paul, MN, USA) & $\begin{array}{l}\text { Breathe Easy }{ }^{\mathrm{TM}} \text { Turbo Unit }(022-00-03) \text { Breathe Easy }{ }^{\mathrm{TM}} \text { Hood (BE - } \\
\text { 10BR) Belt (RBE-BLT) Ni-Mh battery (BP-15) Cartridge (RBE-57-CBRN) }\end{array}$ \\
\hline $\begin{array}{l}\text { Fluid Impervious Coverall } \\
\text { w/Hood and Boots }\end{array}$ & $\begin{array}{l}\text { DuPont (Wilmington, } \\
\text { DE, USA) }\end{array}$ & Tychem $^{\mathrm{TM}} \mathrm{F}$ Coverall (TF169TGY2X000600) \\
\hline Inner Gloves & $\begin{array}{l}\text { Cardinal Health (Dublin, } \\
\mathrm{OH}, \text { USA) }\end{array}$ & Esteem $^{\text {TM }}$ Stretchy Nitrile (8814NB) \\
\hline Outer Gloves (Latex) & $\begin{array}{l}\text { TIDI Products (Neenah, } \\
\text { WI, USA) }\end{array}$ & TIDIShield ${ }^{\mathrm{TM}}$ Powderfree Latex Examination Gloves (BS0460-1) \\
\hline Outer Gloves (Butyl Rubber) & $\begin{array}{l}\text { Showa (Manchester, } \\
\text { UK) }\end{array}$ & Best Butyl Gloves (BST874R3) \\
\hline Tape & $\begin{array}{l}\text { Kappler (Guntersville, } \\
\text { AL, USA) }\end{array}$ & ChemTape $^{\mathrm{TM}}(99402 \mathrm{YW})$ \\
\hline Shoe Covers & $\begin{array}{l}\text { Onguard Industries } \\
\text { (Havre de Grace, MD, } \\
\text { USA) }\end{array}$ & PVC Boot/Shoe Cover (97590) \\
\hline \multicolumn{3}{|l|}{ Intravenous Cannulation } \\
\hline IV Arm/Mannequin & $\begin{array}{l}\text { CAE Healthcare } \\
\text { (Montreal, Quebec, } \\
\text { Canada) }\end{array}$ & $\begin{array}{l}\text { CAE Blue Phantom }{ }^{\mathrm{TM}} \text { IV and Arterial Line Vascular Access Ultrasound } \\
\text { Model (BPA203-NPN) }\end{array}$ \\
\hline Ultrasound & $\begin{array}{l}\text { FUJIFILM SonoSite, Inc. } \\
\text { (Bothell, WA, USA) }\end{array}$ & SonoSite M-Turbo ${ }^{\mathrm{TM}}$ Ultrasound System L25 Venous Transducer \\
\hline \multicolumn{3}{|l|}{ Endotracheal Intubation } \\
\hline Airway Mannequin & $\begin{array}{l}\text { Laerdal (Stavanger, } \\
\text { Norway) }\end{array}$ & Laerdal $^{\mathrm{TM}}$ Airway Management Trainer \\
\hline Video Laryngoscope & $\begin{array}{l}\text { Verathon (Seattle, WA, } \\
\text { USA) }\end{array}$ & GlideScope $^{\mathrm{TM}}$ Advanced Video Laryngoscopy (AVL) system \\
\hline
\end{tabular}

\section{TABLE 1: Study equipment}

NIOSH: National Institute for Occupational Safety and Health; CBRN: chemical, biological, radiological and nuclear

\section{Procedures}

Four stations were set up and fully equipped to perform the necessary tasks: two for intubation and two for intravenous access.

Study subjects were randomized into one of two groups with regard to the sequence of performing procedures, thereby attempting to limit any bias related to the order of procedures. Group 1 performed procedures first without PPE (standard hospital scrubs) and then with PPE, while Group 2 performed procedures first with PPE and then without PPE, as shown in Figure 1. 


\section{Cureus}

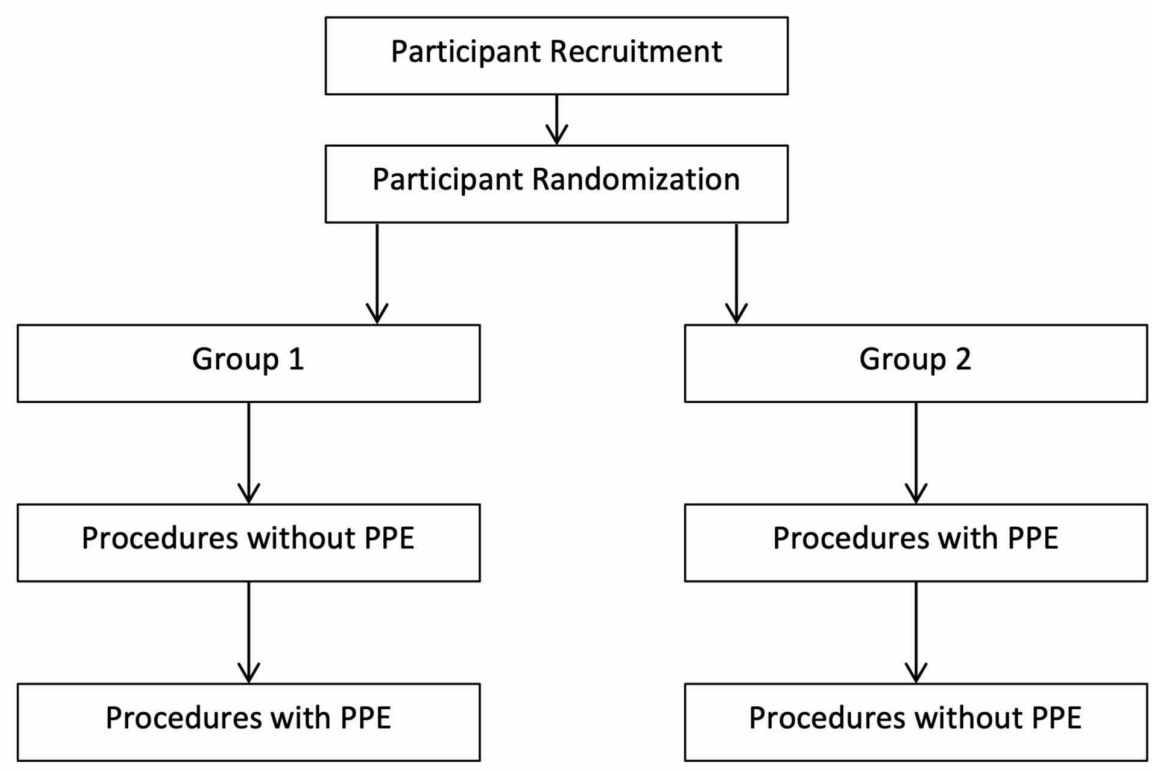

FIGURE 1: Schematic of study protocol

PPE: personal protective equipment

Half of each EM-year was assigned to each group. Subjects donned and doffed PPE under the direction of experts in the appropriate protocols. Each of the subjects was assigned to one of four procedure stations and rotated in sequence as described in Table 2. Upon conclusion of the study, each subject had attempted each skill twice; once while wearing PPE and once while wearing standard clothing. 


\begin{tabular}{|c|c|c|c|c|c|c|c|c|}
\hline \multicolumn{9}{|l|}{ Group 1} \\
\hline Subject & \multicolumn{4}{|l|}{ No PPE } & \multicolumn{4}{|l|}{ PPE } \\
\hline A & IV & IV+US & $\mathrm{DL}$ & VL & IV & IV+US & $\mathrm{DL}$ & VL \\
\hline B & IV+US & IV & DL & VL & IV+US & IV & $\mathrm{DL}$ & VL \\
\hline C & IV & IV+US & VL & $\mathrm{DL}$ & IV & IV+US & VL & $\mathrm{DL}$ \\
\hline D & IV+US & IV & VL & $\mathrm{DL}$ & IV+US & IV & VL & $\mathrm{DL}$ \\
\hline E & DL & VL & IV & IV+US & $\mathrm{DL}$ & VL & IV & IV+US \\
\hline $\mathrm{F}$ & DL & VL & IV+US & IV & $\mathrm{DL}$ & VL & IV+US & IV \\
\hline G & VL & $\mathrm{DL}$ & IV & IV+US & VL & $\mathrm{DL}$ & IV & IV+US \\
\hline H & VL & $\mathrm{DL}$ & IV+US & IV & VL & DL & IV+US & IV \\
\hline \multicolumn{9}{|l|}{ Group 2} \\
\hline Subject & \multicolumn{4}{|l|}{ PPE } & \multicolumn{4}{|l|}{ No PPE } \\
\hline A & IV & IV+US & $\mathrm{DL}$ & VL & IV & IV+US & $\mathrm{DL}$ & VL \\
\hline B & IV+US & IV & DL & VL & IV+US & IV & $\mathrm{DL}$ & VL \\
\hline C & IV & IV+US & VL & $\mathrm{DL}$ & IV & IV+US & VL & $\mathrm{DL}$ \\
\hline D & IV+US & IV & VL & $\mathrm{DL}$ & IV+US & IV & VL & $\mathrm{DL}$ \\
\hline E & $\mathrm{DL}$ & VL & IV & IV+US & $\mathrm{DL}$ & VL & IV & $\mathrm{IV}+\mathrm{US}$ \\
\hline $\mathrm{F}$ & $\mathrm{DL}$ & VL & IV+US & IV & $\mathrm{DL}$ & VL & IV+US & IV \\
\hline G & VL & DL & IV & IV+US & VL & $\mathrm{DL}$ & IV & IV+US \\
\hline H & VL & DL & IV+US & IV & VL & DL & IV+US & IV \\
\hline
\end{tabular}

\section{TABLE 2: Skill station schedule}

IV: intravenous cannulation without ultrasound; IV+US: intravenous cannulation with ultrasound; DL: direct laryngoscopy; VL: video laryngoscopy

Time to successful intubation was recorded for each subject. The procedure start time was recorded when the subject first touched the equipment for preparation. Preparation for intubation included inserting the stylet into the endotracheal tube (ETT), testing ETT balloon inflation, and placing the Macintosh blade onto the laryngoscope handle or the GlideScope ${ }^{\mathrm{TM}}$ (Verathon; Seattle, WA) cover onto the light source. The procedure stop time was recorded when the endotracheal tube (ETT) had been correctly inserted in the trachea with initial inflation of the lungs.

Time to successful IV cannulation was recorded for each subject. The procedure start time was recorded when the subject touched the equipment for preparation. Preparation for this procedure included unwrapping the IV catheter from the package, cleaning the surface of the mannequin, placing ultrasound gel, and turning on the ultrasound machine. The procedure end time was recorded upon the successful initiation of a saline flush of the IV line to confirm proper placement.

All procedure times were recorded in seconds (sec) by volunteers who had experience and knowledge of the skills evaluated. Each subject's times were recorded on standardized data collection forms. No identifying information was recorded on the forms except for EM year. At the conclusion of the study, all forms were collected by the primary investigator. The subjects were then debriefed and given an opportunity to convey their impressions regarding their performance in the skill stations.

\section{Statistical analysis}

The Shapiro Wilk test was utilized to determine if the data fit a normal distribution model. Given the small sample size, a two-tailed Mann-Whitney U test was used to compare the time to perform each procedure with and without PPE. Significance was defined as an associated p-value of $<0.05$. 


\section{Cureus}

\section{Results}

Sixteen of the total 25 eligible EM resident physicians participated in the study. Nine residents were excused because of either scheduling conflicts or work-hour restrictions. Resident participants in the study included two first-year residents (EM-1), 6 second-year residents (EM-2), 3 third-year residents (EM-3) and 5 fourthyear residents (EM-4). One resident's data was excluded from the video laryngoscopy portion due to incomplete data collection.

Data for all four procedures were found to not fit the normal distribution model. Therefore, median times with interquartile range (IQR) are reported below. When performance time was lower with PPE than without $\mathrm{PPE}$, the time is reported as a negative value.

The median time for successful IV cannulation without ultrasound was $95 \mathrm{sec}$ (IQR 73-117 sec) without PPE and 83 (IQR 31-135 sec) with PPE. The median time difference in performing IV cannulation with and without PPE was -9 sec (IQR -45-27 sec, $\mathrm{p}=0.187$ ). The median time for successful intravenous cannulation with ultrasound (IV+US) was $143 \mathrm{sec}$ (IQR 73-124 sec) without PPE and $98 \mathrm{sec}$ (IQR 55-140 sec) with PPE. The median time difference for intravenous cannulation without and with ultrasound was $-47 \mathrm{sec}$ (IQR 162-68 sec, $\mathrm{p}=0.067)$. The specific values per resident are detailed in Tables 3-4.

\begin{tabular}{|c|c|c|c|}
\hline $\begin{array}{l}\text { EM } \\
\text { level }\end{array}$ & $\begin{array}{l}\text { IV without PPE (time in } \\
\text { seconds) }\end{array}$ & $\begin{array}{l}\text { IV with PPE (time in } \\
\text { seconds) }\end{array}$ & $\begin{array}{l}\text { Change in time to perform procedure with PPE (time in } \\
\text { seconds) }\end{array}$ \\
\hline 1 & 88 & 94 & 6 \\
\hline 1 & 87 & 114 & 27 \\
\hline 2 & 109 & $1 / 6$ & 67 \\
\hline 2 & 92 & 82 & -10 \\
\hline 2 & 91 & 89 & -2 \\
\hline 2 & 107 & 84 & -23 \\
\hline 2 & 107 & 65 & -42 \\
\hline 2 & 55 & 54 & -1 \\
\hline 3 & 67 & 59 & -8 \\
\hline 3 & 98 & 59 & -39 \\
\hline 3 & 131 & 68 & -63 \\
\hline 4 & 145 & 118 & -27 \\
\hline 4 & 113 & 118 & 5 \\
\hline 4 & 81 & 53 & -28 \\
\hline 4 & 89 & 115 & 26 \\
\hline 4 & 206 & 63 & -142 \\
\hline Median & 95 & 83 & -9 \\
\hline IQR & 22 & 52 & 36 \\
\hline
\end{tabular}

\section{TABLE 3: Intravenous cannulation without ultrasound}

IV: intravenous; PPE: personal protective equipment 


\section{Cureus}

\begin{tabular}{|c|c|c|c|}
\hline $\begin{array}{l}\text { EM } \\
\text { Level }\end{array}$ & $\begin{array}{l}\text { Ultrasound-guided IV without PPE } \\
\text { (time in seconds) }\end{array}$ & $\begin{array}{l}\text { Ultrasound-guided IV with PPE } \\
\text { (time in seconds) }\end{array}$ & $\begin{array}{l}\text { Change in time to perform procedure with } \\
\text { PPE (time in seconds) }\end{array}$ \\
\hline 1 & 121 & 95 & -26 \\
\hline 1 & 129 & 87 & -42 \\
\hline 2 & 151 & 358 & 207 \\
\hline 2 & 456 & 100 & -356 \\
\hline 2 & 114 & 121 & 7 \\
\hline 2 & 132 & 433 & 301 \\
\hline 2 & 184 & 108 & -76 \\
\hline 2 & 112 & 77 & -35 \\
\hline 3 & 62 & 405 & 343 \\
\hline 3 & 183 & 84 & -99 \\
\hline 3 & 207 & 80 & -127 \\
\hline 4 & 279 & 140 & -139 \\
\hline 4 & 170 & 118 & -52 \\
\hline 4 & 135 & 67 & -68 \\
\hline 4 & 77 & 93 & 16 \\
\hline 4 & 248 & 71 & -177 \\
\hline Median & 143 & 98 & -47 \\
\hline IQR & 71 & 43 & 115 \\
\hline
\end{tabular}

\section{TABLE 4: Intravenous cannulation with ultrasound}

IV: intravenous; PPE: personal protective equipment

The median time for successful intubation with direct laryngoscopy (DL) was $67 \mathrm{sec}$ (IQR 58-76 sec) without PPE and $54 \mathrm{sec}$ (IQR 30-78 sec) with PPE. The median time difference in intubation via direct laryngoscopy with and without PPE was -9 sec (IQR -29-11 sec, $\mathrm{p}=0.159)$. The median time difference in intubation via video laryngoscopy (VL) was $89 \mathrm{sec}$ (IQR 49-130 sec) without PPE and $86 \mathrm{sec}$ (IQR 51-121 sec) with PPE. The median time difference in intubation via video laryngoscopy with and without PPE was -4 sec (IQR -46-38 sec, $\mathrm{p}=0.787$ ). The specific values per resident are specified in Tables 5-6. 


\section{Cureus}

\begin{tabular}{|c|c|c|c|}
\hline $\begin{array}{l}\text { EM } \\
\text { level }\end{array}$ & $\begin{array}{l}\text { Direct laryngoscopy without PPE (time } \\
\text { in seconds) }\end{array}$ & $\begin{array}{l}\text { Direct laryngoscopy } \\
\text { with PPE }\end{array}$ & $\begin{array}{l}\text { Change in time to perform procedure with PPE } \\
\text { (time in seconds) }\end{array}$ \\
\hline 1 & 39 & 68 & 29 \\
\hline 1 & 74 & 131 & 57 \\
\hline 2 & 105 & 75 & -30 \\
\hline 2 & 70 & 52 & -18 \\
\hline 2 & 63 & 42 & -21 \\
\hline 2 & 74 & 66 & -9 \\
\hline 2 & 87 & 50 & -37 \\
\hline 2 & 71 & 37 & -34 \\
\hline 3 & 68 & 59 & -9 \\
\hline 3 & 65 & 54 & -11 \\
\hline 3 & 63 & 54 & -9 \\
\hline 4 & 70 & 66 & -4 \\
\hline 4 & 65 & 104 & 39 \\
\hline 4 & 65 & 34 & -31 \\
\hline 4 & 41 & 41 & 0 \\
\hline 4 & 49 & 42 & -7 \\
\hline Median & 67 & 54 & -9 \\
\hline IQR & 9 & 24 & 20 \\
\hline
\end{tabular}

TABLE 5: Direct laryngoscopy

PPE: personal protective equipment 


\section{Cureus}

\begin{tabular}{|c|c|c|c|}
\hline $\begin{array}{l}\text { EM } \\
\text { level }\end{array}$ & $\begin{array}{l}\text { Video laryngoscopy without PPE } \\
\text { (time in seconds) }\end{array}$ & $\begin{array}{l}\text { Video laryngoscopy with PPE } \\
\text { (time in seconds) }\end{array}$ & $\begin{array}{l}\text { Change in time to perform procedure with } \\
\text { PPE (time in seconds) }\end{array}$ \\
\hline 1 & 74 & 93 & 19 \\
\hline 1 & 92 & 214 & 122 \\
\hline 2 & 87 & 119 & 32 \\
\hline 2 & 128 & 80 & -48 \\
\hline 2 & 59 & 80 & 21 \\
\hline 2 & 160 & 184 & 24 \\
\hline 2 & 54 & 32 & -22 \\
\hline 3 & 89 & 79 & -10 \\
\hline 3 & 90 & 150 & 60 \\
\hline 3 & 54 & 52 & -2 \\
\hline 4 & 255 & 86 & -169 \\
\hline 4 & 98 & 90 & -8 \\
\hline 4 & 80 & 64 & -16 \\
\hline 4 & 70 & 66 & -4 \\
\hline 4 & 291 & 95 & -196 \\
\hline Median & 89 & 86 & -4 \\
\hline IQR & 41 & 35 & 4 \\
\hline
\end{tabular}

\section{TABLE 6: Video-assisted laryngoscopy}

PPE: personal protective equipment

The median time for each procedure with and without PPE is demonstrated in Figure 2.

$$
160
$$

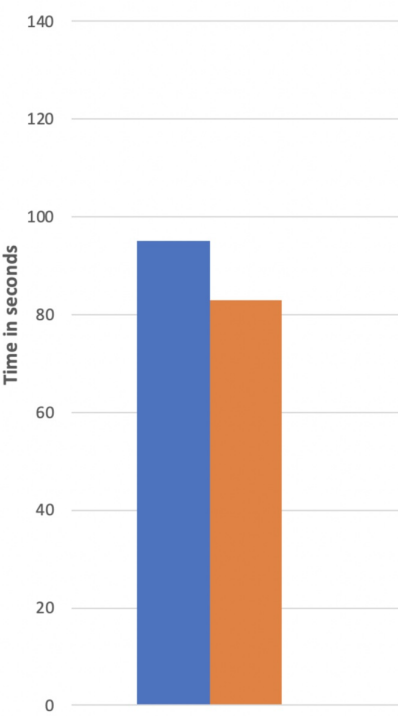

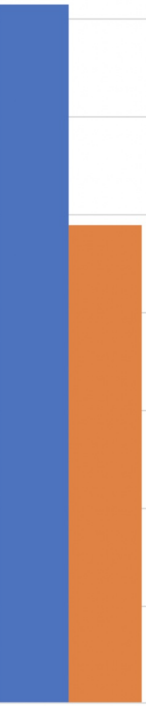

IV + US

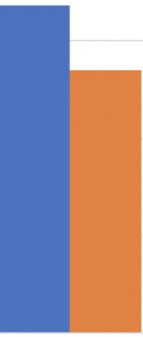

DL

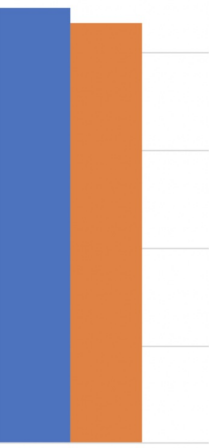

VL

- No PPE $=$ PPE

FIGURE 2: Median difference in time to perform procedure with and 
without PPE

PPE: personal protective equipment

\section{Discussion}

Our study showed that there was not a significant difference related to Level C PPE use for endotracheal intubation with and without the use of adjuncts. Median times were higher using video laryngoscopy as opposed to direct laryngoscopy, but there was no significant difference in the no-PPE and PPE sub-groups. This is not consistent with several studies where there was an increase in intubation time with the use of PPE.

Flaishon et al. in a study of 15 anesthetists showed a statistically significant increase in endotracheal intubation time when using anti-chemical protective gear ( $54 \pm 24 \mathrm{sec}$ vs. $31 \pm 7 \mathrm{sec}, \mathrm{P}<0.01)$ [4]. Garner et al., in a mixed group of paramedics, emergency physicians, and anesthetists noted an increase in time to lung inflation using an endotracheal tube when wearing Level A PPE $(78.6 \pm 23.9 \mathrm{sec}, \mathrm{P}=0.03)$ [5]. Castle et al. evaluated 64 providers and found an increase in the mean completion time of endotracheal intubation (36.1 sec vs. $67.5 \mathrm{sec}$ ) [6].

Consistent with our data, MacDonald et al., in a study of 16 advanced and critical care paramedics, found no statistically significant difference in time to completion of intubation when comparing to a Level C suit (69 sec vs. 79 sec) [7]. In addition, Wang et al. studied 40 emergency physicians (residents) with and without Level C PPE and found no difference in the mean time to successful endotracheal intubation (17.86 sec vs. $17.83 \mathrm{sec}, \mathrm{P}=0.99$ ) [8]. Most recently, Adler et al. studied 65 physicians and nurses with varying levels of PPE and found that there were no significant differences in tasks, including endotracheal intubation, except IV placement (median difference, 5.5 sec vs. $42 \mathrm{sec}, \mathrm{P}<0.01$ ) [9].

We chose to start the time of intubation at the moment the subjects began to prepare equipment for the procedure. Therefore, it is difficult to compare the intubation times in this study with other studies where the start time was post-preparation or insertion of the laryngoscope. However, we felt strongly that this should be included since preparing equipment requires manual dexterity that is influenced by PPE, and in an emergency situation, this preparation will likely be done while donned. Unfortunately, there is limited and somewhat conflicting literature that addresses the question regarding the appropriate time needed to successfully complete airway tasks by otherwise procedurally competent personnel while wearing PPE [4-8]. In our study, the median times for successful intubation with DL and VL (including preparation for intubation), regardless of the use of PPE, were 67 seconds and 89 seconds, respectively. We feel that a time under one and half minutes for preparation and successful endotracheal intubation is an acceptable timeframe.

Similarly, our study showed no significant difference in time for IV cannulation in the no-PPE and the PPE groups, both with and without ultrasound guidance. Although it was not a statistically significant finding, it was interesting that the median times for IV cannulation were faster with PPE than without PPE. Castle et al. found an increase in the mean completion time of IV cannulation when wearing PPE Level C ( $40.8 \mathrm{sec}$ vs. $129.6 \mathrm{sec}$ ) [6]. MacDonald et al. found a statistically significant increase in completion time for IV cannulation when wearing PPE (158 sec vs. 220 sec, P < 0.01) [7]. There has also been no previously established appropriate time for IV placement using PPE; however, the median time for IV cannulation with ultrasound using PPE was 98 seconds. We feel that successful IV cannulation under two minutes is an appropriate time frame.

However, our study has a few limitations. First, the participant group was small thereby making statistical analysis challenging. As a result, we were unable to parse out subtle differences in proficiency that might occur across varying training levels. Second, we did not track the time taken for each individual stage of the procedure; that is, specific time for preparation, time from the insertion of the laryngoscope to passing the ETT and lung inflation. This would have been beneficial in making a direct comparison of our results to existing literature. Finally, while our participant group of trainees completed the procedures in what we consider an appropriate time frame, future studies should include a group of experienced clinicians so that a "gold standard" can be introduced for comparison.

\section{Conclusions}

In this study, we demonstrate that there is no significant difference in completion time for any of the studied procedures with and without Level C PPE, with no advantage related to the use of adjuncts such as ultrasound and video laryngoscopy. Maintenance of existing skill proficiency while wearing PPE is a key finding and perhaps obviates the need for continuous, skills-focused PPE training. A safe and cost-effective strategy might be to conduct basic, just-in-time PPE training for personnel who have maximal proficiency in the relevant emergency skill. 


\section{Additional Information \\ Disclosures}

Human subjects: Consent was obtained by all participants in this study. Rutgers Newark Health Sciences IRB issued approval Pro20140000949. The study was approved by the Institutional Review Board of Rutgers Newark Health Sciences. Animal subjects: All authors have confirmed that this study did not involve animal subjects or tissue. Conflicts of interest: In compliance with the ICMJE uniform disclosure form, all authors declare the following: Payment/services info: All authors have declared that no financial support was received from any organization for the submitted work. Financial relationships: All authors have declared that they have no financial relationships at present or within the previous three years with any organizations that might have an interest in the submitted work. Other relationships: All authors have declared that there are no other relationships or activities that could appear to have influenced the submitted work.

\section{Acknowledgements}

The authors would like to acknowledge Christine Ramdin, PhD, for her guidance with statistical analysis.

\section{References}

1. World Health Organization: Public health preparedness and response. Public Health Response to Biological and Chemical Weapons: WHO Guidance. WHO, Geneva, Switzerland; 2004. 60.

2. U.S. Department of Labor, Occupational Safety and Health Administration. Personal protective equipment . (2020). Accessed: March 10, 2020: https://www.osha.gov/SLTC/personalprotectiveequipment/.

3. Helman S, Lisanti AJ, Adams A, Field C, Davis KF: Just-in-time training for high-risk low-volume therapies: an approach to ensure patient safety. J Nurs Care Qual. 2016, 31:33-39. 10.1097/NCQ.0000000000000131

4. Flaishon R, Sotman A, Ben-Abraham R, Rudick V, Varssano D, Weinbroum AA: Antichemical protective gear prolongs time to successful airway management: a randomized, crossover study in humans. Anesthesiology. 2004, 100:260-266. 10.1097/00000542-200402000-00013

5. Garner A, Laurence H, Lee A: Practicality of performing medical procedures in chemical protective ensembles. Emerg Med Australas. 2004, 16:108-113. 10.1111/j.1742-6723.2004.00560.x

6. Castle N, Owen R, Hann M, Clark S, Reeves D, Gurney I: Impact of chemical, biological, radiation, and nuclear personal protective equipment on the performance of low- and high-dexterity airway and vascular access skills. Resuscitation. 2009, 80:1290-1295. 10.1016/j.resuscitation.2009.08.001

7. MacDonald R, LeBlanc V, McArthur B, Dubrowski A: Performance of resuscitation skills by paramedic personnel in chemical protective suits. Prehosp Emerg Care. 2006, 10:254-259. 10.1080/10903120500541076

8. Wang C-C, Chaou C-H, Tseng C-Y, Lin C-C: The effect of personal protective equipment on emergency airway management by emergency physicians: a mannequin study. Eur J Emerg Med. 2015, 23:124-129. 10.1097/MEJ.0000000000000157

9. Adler MD, Krug S, Good GL, et al.: Impact of personal protective equipment on the performance of emergency pediatric tasks [Epub ahead of print]. Pediatr Emerg Care. 2020, 24:10.1097/PEC.0000000000002028

10. Claret PG, Bobbia X, Asencio R, et al.: Comparison of the Airtraq laryngoscope versus the conventional Macintosh laryngoscope while wearing CBRN-PPE. Eur J Emerg Med. 2016, 23:119-123. 10.1097/mej.0000000000000220

11. Bhandari G, Shahi KS, Asad M, Bhakuni R: Airtraq versus Macintosh laryngoscope: a comparative study in tracheal intubation. Prehosp Disaster Med. 2015, 30:259-263. 10.4103/0259-1162.118971

12. Aberle SJ, Sandefur BJ, Sunga KL, et al.: Intubation efficiency and perceived ease of use of video laryngoscopy vs direct laryngoscopy while wearing HazMat PPE: a preliminary high-fidelity mannequin study. Prehosp Disaster Med. 2015, 30:259-263. 10.1017/S1049023X15004707

13. Vitto MJ, Myers M, Vitto CM, Evans DP: Perceived difficulty and success rate of standard versus ultrasoundguided peripheral intravenous cannulation in a novice study group: a randomized crossover trial. J Ultrasound Med. 2016, 35:895-898. 10.7863/ultra.15.06057

14. Liu YT, Alsaawi A, Bjornsson HM: Ultrasound-guided peripheral venous access: a systematic review of randomized-controlled trials. Eur J Emerg Med. 2014, 21:18-23. 